\title{
Projetos de aprendizagem: percursos da iniciação científica no Projeto Amora
}

\author{
Rosália Procasko Lacerda* \\ Italo Modesto Dutra ${ }^{* *}$
}

\begin{abstract}
Resumo: Este artigo trata das possibilidades da iniciação científica na educação básica, descrevendo, especialmente, a metodologia de projetos de aprendizagem desenvolvida no Projeto Amora do Colégio de Aplicação da UFRGS. Epistemologicamente, esta proposta fundamenta-se na concepção de que o conhecimento é uma construção do próprio sujeito a partir de suas ações e interações com o objeto. Decorrem dessa concepção, ações e estratégias pedagógicas que dão suporte à iniciação científica como espaço que oportuniza ao aluno pensar, indagar e explicar a realidade e suas constantes transformações. Fazem parte dessas ações pedagógicas a formulação da pergunta, a elaboração de mapas conceituais e a confecção de uma wiki.
\end{abstract}

Palavras-chave: Iniciação científica; Projeto de aprendizagem; Mapa conceitual; Tecnologia digital.

Abstract: The article discusses the possibilities of undergraduate research in basic education, especially describing the methodology of learning projects developed in Colégio de Aplicação -

* Doutoranda em Informática na Educação (UFRGS); Mestre em Estudos da Linguagem (UFRGS); Licenciada em Letras (UFRGS); docente do Departamento de Comunicação do CAp/UFRGS. E-mail: rosalia.lacerda@ufrgs.br.

* Doutor em Informática na Educação (UFRGS); Mestre em Matemática (UFRGS); Licenciado em Matemática (FURG); docente do Departamento de Ciências Exatas e da Natureza do CAp/UFRGS cedido ao Ministério de Educação. E-mail: italo. dutra@ufrgs.br. 
UFRGS. Epistemologically this proposal is based on the concept that knowledge is a construction of the subject from their actions and interactions with the object. Actions flow from this design and pedagogical strategies that support undergraduate research space that gives opportunity to the student think, inquire and explain reality and your constant changes. Among these pedagogical actions the formulation of questions, the development of concept maps and the making of a wiki.

Keywords: Scientific initiation; Learning projects; Conceptual map; Digital technology.

\section{Introdução}

O homem é um ser que naturalmente quer descobrir, conhecer, investigar e todas as aprendizagens que daí decorrem são reconhecidas primeiramente pelas experiências que já tivemos, as quais representam nosso sistema de significações. Em uma proposta metodológica tradicional, o conhecimento é transmitido principalmente através do professor, pelo texto escrito, pelo livro didático e por um eventual experimento mostrado aos alunos. Os conteúdos são de domínio absoluto do professor, que também faz a escolha e propõe uma ordem sequencial de apresentação. Quanto mais domínio e clareza possuir o professor ao transmitir as informaçốes, maiores serão as chances de os alunos aprenderem. À medida que o aluno é percebido como agente de sua própria aprendizagem, essa concepção sofre mudanças, sendo requerida uma conduta mais ativa do estudante e sendo pensadas atividades que o impulsionem a descobrir, a pensar, a formular indagações e a elaborar possíveis respostas.

Sem dúvida, não é apenas na sala de aula que circulam conceitos, noções e impressões a respeito da ciência e do fazer científico. Os constantes avanços da comunicação e da tecnologia têm viabilizado novas formas de aprendizagem, de construção, de 
registro e de armazenamento do conhecimento, possibilitando, assim, maior facilidade em seu acesso, comunicação e uso no dia a dia. Mas a imagem que estudantes fazem da ciência ainda está associada a um conjunto de descobertas feitas por cientistas em condições particulares de trabalho, as quais são comunicadas por meio de diversas mídias à população em geral. Como resultado dessa visão, não raro, crianças e adolescentes associam ao cientista a imagem estereotipada de um homem que desenvolve pesquisas em um laboratório cercado por tubos de ensaio.

Em consonância com as mudanças emergentes na sociedade do século XXI, o Projeto Amora, desenvolvido no Colégio de Aplicação desta Universidade desde o ano de 1996, tem-se proposto a redimensionar as relaçóes professor/aluno/conhecimento, bem como o currículo que integra as Tecnologias da Informação e da Comunicação (TIC) como recursos de criação, manejo e publicação de informações e conhecimentos produzidos por seus participantes (estudantes e docentes). É assim que diversas situações pedagógicas são pensadas pelos professores com o objetivo de conhecer as ideias dos alunos, dando vazão às suas curiosidades e necessidades, bem como a suas crenças e vivências. A proposta de iniciação científica, nesse cenário, toma forma na metodologia de projetos de aprendizagem, abrindo-se espaço para a indagação genuína do estudante e para a inter-relação entre os diversos campos do conhecimento, configurando-se, assim, um aprender intimamente relacionado às oportunidades de construir significados e gerar explicações para os fenômenos e fatos do cotidiano.

\section{A iniciação científica na escola}

Fazer iniciação científica na escola não significa reproduzir os passos de projetos desenvolvidos por cientistas ou pesquisadores universitários. Significa, isto sim, diante das constantes revoluções científicas e tecnológicas a que estamos expostos, 
dar oportunidade ao aluno de refletir, pensar, indagar e buscar formas de explicar e transformar a realidade. Só há sentido no trabalho, com iniciação científica na escola, quando oferecem-se elementos para que o estudante elabore tentativas de explicação que deem conta das mudanças e das transformações que observa.

Não é preciso, para tanto, conhecer tudo sobre determinado assunto nem obter todas as respostas para as indagações formuladas. Nem sempre significa chegar à compreensão mais correta de um conceito, nem optar pelo melhor método. No entanto, significa estar preparado para se defrontar com a novidade, surpreendendo-se com ela a ponto de formular uma questão de pesquisa. Mais que isso, significa buscar caminhos de compreender melhor sua própria curiosidade, desenvolvendo recursos cognitivos e assumindo os riscos dos equívocos, da incompletude e da provisoriedade do conhecimento.

Ainda que os passos do método científico organizem e contribuam para a produção do conhecimento, eles nem sempre dão conta dos caminhos percorridos pela pesquisa. Dessa maneira, ao invés da sequência clássica do método científico (observação, levantamento de hipóteses, realização de experimento, coleta de resultados, interpretação e elaboração de conclusões), pode-se pensar na formulação da pergunta, nas ideias prévias sobre o assunto, na antecipação de uma possível hipótese, na justificativa da escolha e no registro das descobertas. Tais etapas são inter-relacionadas na medida em que umas fundamentam as outras e todas implicam a busca de certezas.

\section{O percurso da pesquisa no Projeto Amora: teoria e prática}

A iniciação científica na escola de educação básica deve ter como ponto de partida a indagação, sem se preocupar em classificar assuntos e conteúdos nas disciplinas do currículo, mas abrindo espaço para as relaçóes que podem ser estabelecidas entre os 
diferentes campos do conhecimento. Para abrigar essa proposta, é necessária uma metodologia que privilegie a ação do sujeito e que se fundamente na concepção de que esse mesmo sujeito conhece o mundo a partir de suas próprias estruturas. Decorre desse entendimento, a proposta metodológica desenvolvida no Projeto Amora, descrita a seguir.

\section{O trabalho com projetos e o suporte epistemológico}

O termo projeto tem sido usado largamente na educação com a finalidade de resgatar, na escola, o espaço da curiosidade, aproximando a sala de aula do que, de fato, representa a realidade e, talvez, o interesse do aluno. Alguns autores apontam para a existência do termo projeto já no século $\mathrm{XV}$, quando do desenvolvimento de pesquisas cujo planejamento prévio era feito por projetos.

A necessidade de transformar a escola não é atual; já no início do século XX surge a Pedagogia de Projetos, como um questionamento aos princípios da escola tradicional. Esse movimento resultou de pesquisas de educadores europeus (Montessori, Decroly, Claparède e outros) e representantes da América do Norte, como Jonh Dewey e William Kilpatrick. Esses últimos criaram o Método de Projetos com a finalidade de promover uma mudança na escola em relação ao currículo, muito mais voltada a uma epistemologia que acredita na construção do conhecimento pelo próprio sujeito.

Fernando Hernandez e Jurjo Santomé, na década de 90, questionam o currículo na forma tradicional como está organizado, propondo mudanças a partir dos projetos de trabalho. Uma perspectiva não linear de organização curricular associada à articulação dos saberes em sala de aula constituem a mudança proposta pelos autores. O projeto, nessa perspectiva, não é visto como metodologia, mas como desencadeador de um processo reflexivo que gera transformações. Dessa forma, um desafio, uma situação de conflito ou algo inquietante para alunos e professores 
pode desencadear um projeto, já que este está alicerçado na construção ativa de significados.

Os projetos de aprendizagem são defendidos por Fagundes (1999) como uma metodologia de aprendizagem, a qual dá suporte aos questionamentos formulados pelos próprios alunos a partir de suas curiosidades. Partindo do conhecimento prévio construído com base em experiências anteriores, o sujeito irá formular uma questão de pesquisa motivado por aquilo que lhe perturba o sistema de significações. A metodologia de projetos de aprendizagem baseia-se na concepção de que o próprio sujeito é o responsável por sua aprendizagem, na medida em que ele só aprende se interage e tal interação somente acontece se houver um interesse particular desse mesmo sujeito. Em decorrência, o aluno conhece o objeto (entendido aqui como tudo o que lhe desperta o interesse) a partir de suas estruturas e, no processo de interação com esse objeto, modifica tais estruturas, ampliando e enriquecendo o sistema de relações.

A iniciação científica no Projeto Amora é desenvolvida por meio da metodologia de projetos de aprendizagem. Esses projetos fundamentam-se em outra concepção espaço-temporal de currículo e planejamento: conteúdos, formas e horários não são previamente definidos ou estipulados pelo grupo de professores, mas pensados de maneira concomitante e, fundamentalmente, a partir das demandas originadas pelas dúvidas dos alunos. Essa conduta pedagógica não exclui o planejamento, de forma alguma, o ressignifica à medida que não parte de ações organizadas exclusivamente sob o ponto de vista do professor, mas do que os docentes já sabem dos alunos, do que conhecem de suas áreas de formação e de suas hipóteses sobre as aprendizagens e interesses dos estudantes.

Com o passar do tempo, algumas etapas e estratégias foram consolidando-se no Projeto Amora, sendo consideradas pela equipe de professores como fundamentais para o desenvolvimento do trabalho com projetos, quais sejam: as atividades exploratórias, os mapas conceituais e o registro virtual. Tais 
procedimentos nascem da necessidade de se compreender mais aprofundadamente como o aluno se relaciona, através da experiência, com o que é exterior e com a novidade, relacionando e organizando novos elementos às estruturas e aos esquemas que possui. São essas ações pedagógicas que serão descritas a seguir.

\section{Ações pedagógicas: etapas e estratégias}

Fazer ciência requer a construção de novas competências ou capacidades cognitivas e, além disso, de novas açôes pedagógicas que ampliem a perspectiva do aluno, ampliando-lhe as possibilidades de pensar e representar as ideias. É por esse motivo que algumas ações são indispensáveis à rotina de sala de aula no Projeto Amora, como descrevemos a seguir.

\section{Atividades exploratórias e formulação da pergunta}

As atividades exploratórias têm sido concebidas como açôes disparadoras que permitem ao aluno perceber o entorno e o mundo de diferentes maneiras, ampliando seu ponto de vista.

Inicialmente, um conjunto de atividades são organizadas e propostas aos alunos com o objetivo de fazê-los pensar sobre o que é ciência, quem faz ciência e como fazer ciência na escola. Muitas vezes, os alunos já experimentaram a iniciação científica sem se dar conta disso. Cabem às atividades exploratórias oportunizar uma reflexão acerca das relações entre os fatos do cotidiano e a ciência, entre o que percebem e os porquês relacionados, entre o intuitivo e o conhecimento científico. 
Figura 1: Iniciação Científica no Projeto Amora

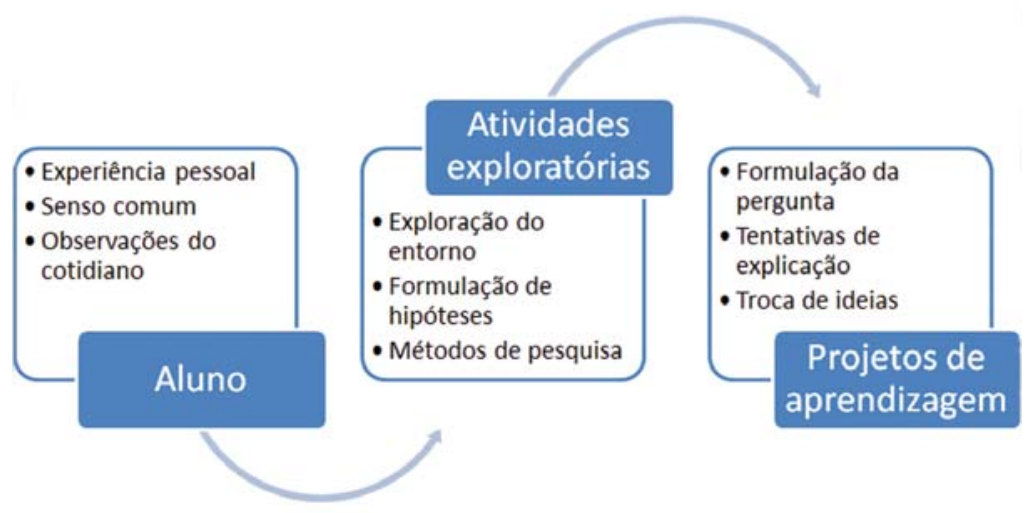

Fonte: Acervo Pessoal dos autores.

São exemplos de atividades exploratórias ações que oportunizem aos estudantes utilizar os recursos da tecnologia digital para visitar e revisitar espaços desconhecidos ou distantes da escola; observar os fenômenos da natureza e do espaço físico em que a escola está inserida; entrar em contato com distintos campos do conhecimento que não apenas as ciências naturais; elaborar questionamentos acerca de como as coisas funcionam e sobre os problemas da atualidade. Esses são apenas alguns exemplos de como promover uma abertura de possibilidades em sala de aula; cada nova ideia ou possibilidade que surge na interação do aluno com outros sujeitos ou com diferentes objetos pode representar a construção de novidades e a abertura para novas possibilidades.

Durante essas propostas de trabalho, os alunos deparam-se com fatos ou fenômenos desconhecidos, com situações curiosas e inusitadas, com questões para as quais ainda não têm resposta, com formas de perceber o mundo ainda não experimentadas. É nesse contexto de exploração e criação que, em uma segunda etapa, o estudante é convidado a formular sua pergunta de investigação. A pergunta, portanto, está ancorada nas significações já construídas 
pelo aluno (conhecimento prévio) e representa a perturbação do sujeito diante da novidade ou seja daquilo que lhe interessa por estar temporariamente sem resposta ou sem solução. A pergunta formulada pelo sujeito, de certa forma, dá concretude à curiosidade desencadeada pelo processo exploratório. Seguem-se alguns exemplos de questóes formuladas pelos alunos:

Quadro 1: Perguntas formuladas por alunos do Projeto Amora

Se as cobras venenosas usam o veneno como defesa, o que as não venenosas fazem?

Por que os cães correm atrás de gatos e por que os gatos correm atrás de ratos?

A formulação da questão de investigação, a explicitação do que já se conhece a respeito do assunto, bem como as dúvidas secundárias que surgem a partir da primeira pergunta, caracterizam o processo interno do indivíduo que lhe permite perceber os erros e as lacunas de compreensão dos fenômenos e ações. Por essa razão, são fundamentais a compreensão desse processo por parte do professor e sua intervenção no sentido de compreender o desenvolvimento cognitivo do aluno. Acompanha, também, a pergunta de investigação, uma hipótese também formulada pelo aluno. Essa hipótese não se refere a uma proposição a ser confirmada ou refutada como na metodologia científica, mas a um conjunto de ideias prévias sobre as quais está ancorada a pergunta do estudante. São concepções que representam o ponto de partida para a compreensão dos fatos em estudo. Ao formular a pergunta e a hipótese, o aluno começa a ter clareza do que já sabe e, mais ainda, de que isso ainda é insuficiente para dar conta de sua curiosidade. É parte constituinte dessa etapa do trabalho, discutir com os estudantes sobre as várias formas de se encontrar respostas aos questionamentos feitos. Essa etapa busca refletir sobre as melhores maneiras de se chegar à resposta ou à solução de determinado desafio, oportunizando ao aluno uma reflexão sobre diferentes métodos de pesquisa. 


\section{Os mapas conceituais}

Os mapas conceituais são uma forma de representação do conhecimento que parte de conceitos ou palavras-chave sobre determinada temática, representando, assim, o conjunto de significações construídas sobre tal assunto. A partir dos conceitos ou palavras-chave selecionados, são estabelecidas ligações formando-se proposições.

A representação do conhecimento através dos mapas conceituais tem sido estratégia fundamental de intervenção dos professores quando orientam os projetos de aprendizagem dos alunos, justamente porque permite uma aproximação à forma de pensar do estudante. Dessa maneira, ficam evidentes as certezas, as ideias incompletas e as contradições no pensamento do autor do mapa, conforme exemplo a seguir:

Figura 2: Primeira e segunda versões de mapas conceituais elaborados pelo mesmo aluno

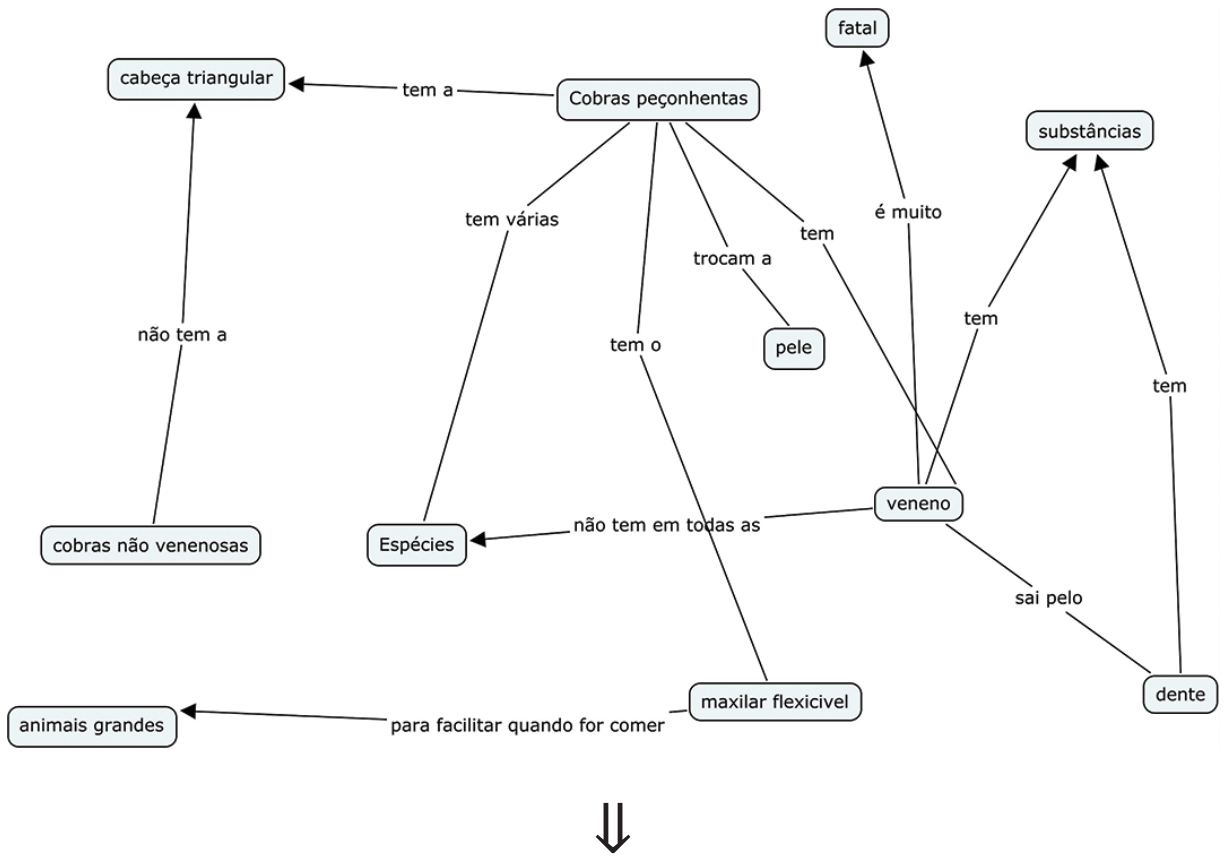




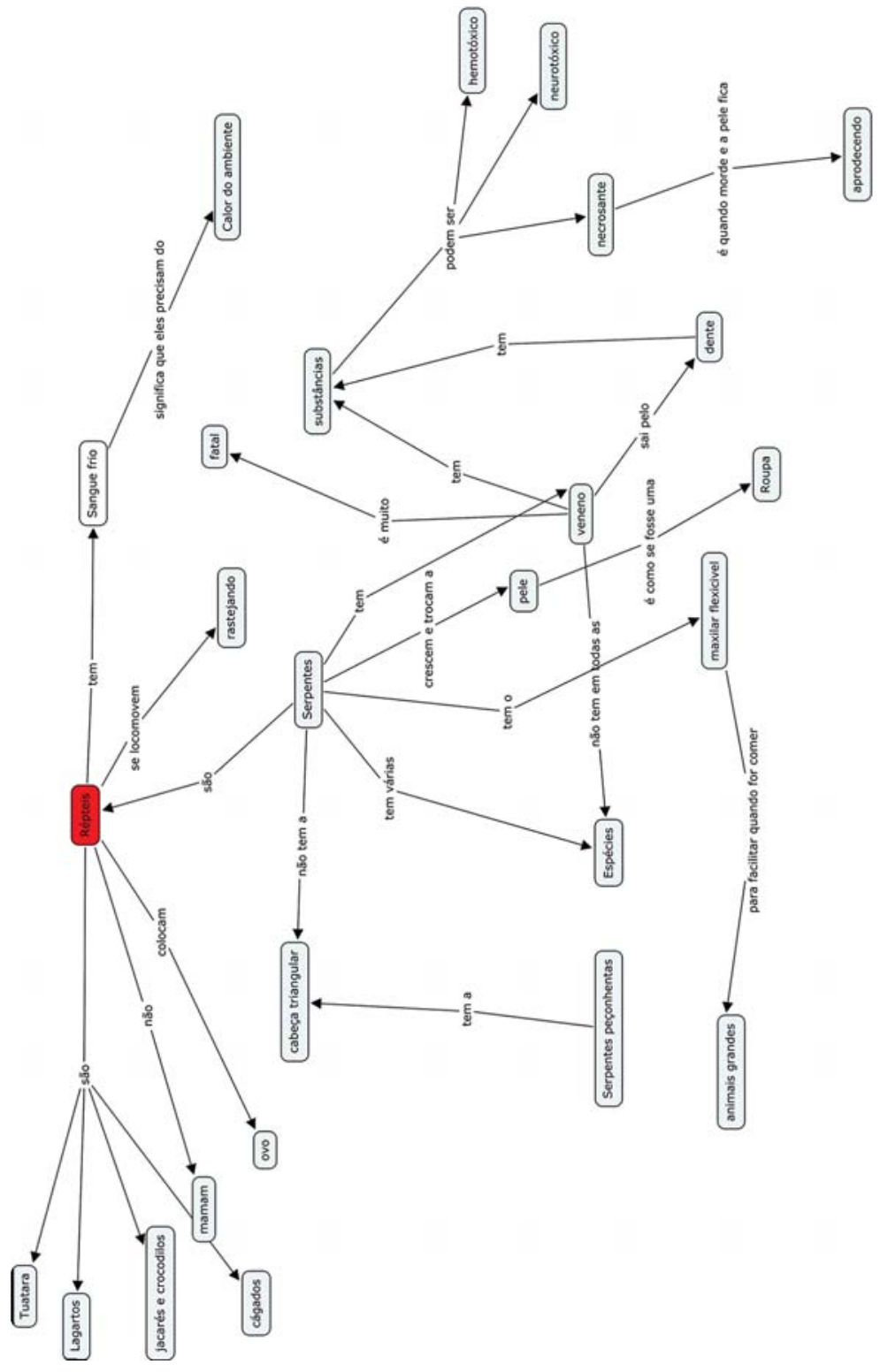

Fonte: Acervo Pessoal dos autores. 
A prática do uso de mapas conceituais ${ }^{1}$ vem se desenvolvendo no Projeto Amora desde 2006, com o uso da ferramenta CMap Tools, confeccionada no Institute for Human and Machine Cognition, da University of West Florida, a qual permite construir mapas conceituais e publicá-los em servidores, assim como transformá-los em figuras que podem ser publicadas em páginas da Internet.

O mapa conceitual é, portanto, uma outra forma de representar as ideias. Conforme Dutra (2006), essa forma de representação torna acessíveis as relações estabelecidas entre os conceitos ou noções. Parte-se, assim, da concepção de que um conceito é formado por outros conceitos, criando-se um sistema de significaçóes que expressa o entendimento do aluno acerca dos conceitos conectados, percebendo de forma mais clara a lógica do estudante ao relacionar determinados elementos.

Nesse sentido, a elaboração sistemática de mapas conceituais digitais pelos alunos, acompanhada de uma intervenção cuidadosa do professor, podem contribuir muito para o acompanhamento dos processos de conceituação dos estudantes.

\section{Wikis}

O Projeto Amora, desde seu início em 1996, apostou no uso da tecnologia digital como forma de registro e compartilhamento das produções de professores e alunos. Dessa forma, o percurso das investigaçóes dos alunos é publicado em páginas virtuais por eles confeccionadas. Nos anos iniciais do projeto, as páginas eram construídas com editores como o Mozilla Composer ou o Microsoft Frontpage Express, para posterior publicação em um servidor. As dificuldades técnicas de armazenamento dos dados e o uso de uma linguagem específica para a publicação no

\footnotetext{
1 Essa prática foi iniciada pelo Prof. Italo Dutra, em sua tese de doutorado. Estão disponíveis maiores informações no artigo "Blog, wiki e mapas conceituais digitais no desenvolvimento de Projetos de Aprendizagem com alunos do Ensino Fundamental”, publicado na Revista Renote do Centro Interdisciplinar de Novas Tecnologias na Educação - UFRGS.
} 
servidor, fez com que o grupo de professores optasse por uma forma de registro online. Assim, desde 2005, o registro virtual se dá por meio da ferramenta $P B$ works que não requer o domínio de linguagens de programação e, ao mesmo tempo, oportuniza o armazenamento de imagens, postagem de comentários, histórico de revisões e limitada customização de interface (SCHÄFER; FAGUNDES; LACERDA, 2009). Desse modo, o conteúdo elaborado pelo aluno e publicado na wiki envolve o conjunto de descobertas do estudante, apresentadas ao longo do hipertexto, duas versões do mapa conceitual e as multimídias utilizadas no hiperdocumento.

Figura 3: Frontpage da wiki de um grupo de alunos
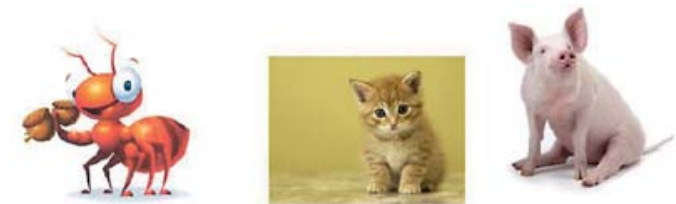

Bem vindo(a) a página virtual com pesquisas sobre animais da terceira edição de projetos do Colégio de Aplicação, orientadas pelas professoras Gláucia de Souza e Rosália Lacerda!

Acesso as pesquisas:

Formigas Gatos Porcos Faisão Ganso Caturrita
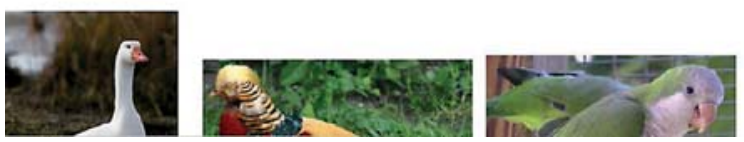

Fonte: Acervo Pessoal dos autores.

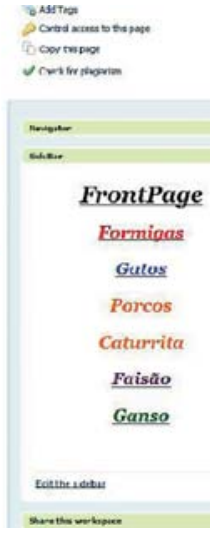

FrontPage

Gutos

Porcos

Caturrita

Faisẫo

inso

No ano de 2010, o Colégio de Aplicação passou a integrar o Projeto Um Computador por Aluno (UCA) como escola-piloto, recebendo laptops para todos os alunos e professores da escola. Em consequência disso, potencializaram-se o acesso à internet e os usos da tecnologia digital para o registro virtual das atividades desenvolvidas, uma vez que cada aluno tem à sua disposição um computador conectado à rede.

2 Disponível em: <http://amora201 lanimaisterceiraedicao.pbworks.com/w/ page/47639057/FrontPage $>$ 


\section{Considerações finais}

Ainda que o tempo e as diferentes configurações das equipes de professores-pesquisadores do Amora tenham modificado as características e as rotinas desenvolvidas desde o seu início, sem dúvida, o modelo de iniciação científica, por meio da metodologia de projetos de aprendizagem, tem-se consolidado ao longo da existência do Projeto.

As transformaçốes pelas quais passou o Amora reforçam sua intenção de redimensionar o currículo, agora não apenas integrando as TIC, mas ampliando possibilidades de alunos e professores mediante o uso do laptop educacional no modelo 1:1. Frente a essas inovações, novas necessidades surgem e novas ideias e instrumentos se tornam fundamentais para acompanhar e qualificar, ainda mais, as aprendizagens dos estudantes em um contexto de autoria e interação permanentes.

\section{Referências}

DUTRA, Ítalo Modesto; PICCININI, Carlos Augusto; BECKER, Julia Lângaro; JOHANN, Stéfano Pupe; FAGUNDES, Léa da Cruz. Blog, wiki e mapas conceituais digitais no desenvolvimento de Projetos de Aprendizagem com alunos do Ensino Fundamental. Revista Novas Tecnologias na Educação, Porto Alegre, v. 4, n. 1, 2006.

ESPINOZA, Ana Maria. Ciências na escola: novas perspectivas para a formação dos alunos. São Paulo: Ática, 2010.

FAGUNDES, Léa da Cruz. Aprendizes do futuro: as inovações começaram. Coleção Informática. Disponível em: <http://mathematikos.psico. ufrgs.br/textos/aprender.pdf >. Acesso em 27 abr. 2013.

MAGDALENA, Beatriz Corso; COSTA, Iris Elisabeth Tempel. Internet em sala de aula: com a palavra, os professores. Porto Alegre: Artmed, 2003.

SCHÄFER, Patrícia Behling; LACERDA, Rosália Procasko; FAGUNDES, Léa da Cruz. Escrita colaborativa na cultura digital: ferramentas e possibilidades de construção do conhecimento em rede. Revista Novas Tecnologias na Educação, Porto Alegre, v. 7, n. 1, 2009. 